\title{
Evaluation of safety, efficacy, acceptance and expulsion of post placental intrauterine contraceptive device in a tertiary care centre
}

\section{Geetha Mahadevan, Nithya Chandika B.*}

Department of Obstetrics and Gynecology, Institute of Obstetrics and Gynaecology, Egmore, Chennai, Tamil Nadu India

Received: 20 November 2017

Accepted: 19 December 2017

*Correspondence:

Dr. Nithya Chandika B.,

E-mail: nithyachandika@gmail.com

Copyright: () the author(s), publisher and licensee Medip Academy. This is an open-access article distributed under the terms of the Creative Commons Attribution Non-Commercial License, which permits unrestricted non-commercial use, distribution, and reproduction in any medium, provided the original work is properly cited.

\begin{abstract}
Background: Postpartum intrauterine device provides an effective temporary method of contraception for the woman who needs birth spacing rather than birth limitation and also a quasi-permanent family planning method. The aim of this study was to study the efficacy, acceptance, safety and complication of PPIUCD insertion.

Method: This a retrospective analytical study done in a tertiary care teaching institute, Institute of Obstetrics and Gynaecology Egmore for a six-year period from January 2010 to December 2015 with a sample size of 81204 . Outcomes measured were safety, efficacy, acceptance (patients and professionals) and complications.

Results: For the study period of six years the total number of women delivered were 81204 . A steady increase was noted in the insertion of PPIUCD from 2010 (1.98\%) to 2015 (58\%). 50.5\% had insertion following caesarean section and $49.5 \%$ following vaginal delivery. Primipara had a higher rate of acceptance amounting to $74.74 \%$. Most common complication reported was missing strings $9.25 \%$ and a greater part of the patients (83\%) did not have any complaints.

Conclusions: Enthusiasm and conviction on the part of the health care provider goes a long way in improving the acceptance rate of PPIUCD. It is an indispensable contraceptive tool for our country since our women most often do not return for postnatal contraceptive options.
\end{abstract}

Keywords: PPIUCD, Expulsion, Perforation, Kellys placental forceps

\section{INTRODUCTION}

India with the world's fastest growing population is in an urgent need for a safe and widely acceptable contraceptive method. The unmet need of family planning in India is $21.3 \%$ as per DLHS-III (2007-08). ${ }^{1}$ Also the spacing of child birth is inadequate.

Spacing between two childbirths is less than the recommended period of 3 years in $57.4 \%$ of births (SRS 2012). $46 \%$ of women have spacing less than 30 months. ${ }^{1}$ Reducing unwanted pregnancies in the immediate postpartum period brings about a drastic reduction in the maternal and child mortality rate including those among adolescent women and unsafe abortions. Family planning can avert nearly one-third of maternal deaths and $10 \%$ of child mortality when couples space their pregnancies more than two years apart Janani Suraksha Yojana introduced under the National Rural Health Mission in 2005, has contributed to the increase in the total number of institutional deliveries. ${ }^{2}$

In order to capitalize on the opportunity provided by increased institutional deliveries, the Government of India is focusing on strengthening post-partum family planning services. ${ }^{1}$ According to statistics by the National Family Health Survey 4 (2015-2016) institutional deliveries are as high as $99 \%$ in Tamil Nadu. Thus, 
PPIUCD provides a golden opportunity to provide effective contraception to this major share of population who deliver in hospitals.

\section{METHODS}

This is a retrospective analytical study of the prospectively collected data conducted at the Institute of Obstetrics and Gynaecology Egmore for a six-year period from January 2010 to December 2015. Insertion was done by trained obstetricians who followed all recommended clinical and infection prevention measures for successful insertion as per the national family welfare guidelines. All patients were given adequate counselling right from the period of antenatal visits.

\section{Inclusion criteria}

- Women fulfilling WHO medical eligibility criteria.

- Women who gave informed written consent and had either vaginal delivery or caesarean section.

Patients were subdivided into three categories based on timing of insertion and mode of delivery. Postplacental insertion was done within 10 minutes of delivery in labor ward.

Immediate postpartum insertion was done within 48 hours of delivery in post-natal ward. Intracaesareaninsertion that takes place during a cesarean delivery, after removal of the placenta and before closure of the uterine incision. This data was entered in registers maintained at the labour Ward, postnatal ward and operation theatre.

\section{Exclusion criteria}

- Women with history of prolonged rupture of membranes ( $>18$ hours)

- Chorioamnionitis

- Distorted uterine cavity

- Unresolved post-partum hemorrhage.

\section{Insertion technique}

Post placental insertion was done using Kellys placental forceps which is inserted up to uterine fundus and IUCD is released using the no touch technique.

- Immediate postpartum insertion can be done even with a ring forceps.

- Intracaesarean-IUCD is introduced through the uterine incision during caesarean section and placed at the uterine fundus. This is done manually or using a regular ring forceps, since it is not necessary to use a long instrument to reach the fundus. Follow up was done at 6 weeks postpartum in the Department of Family Planning where complaints like missing thread, expulsion were recorded in the respective registers.

\section{RESULTS}

Outcomes studied were acceptance based on year of insertion, parity, mode of delivery and complaints during follow up.

\section{Year wise insertion}

During the six-year study period from January 2010 to December 2015, total number of deliveries were 81204 of which PPIUCD acceptance was 25435. Although the number of deliveries has remained almost the same, there is an obvious increasing trend in acceptance from 2010 $(1.99 \%)$ to $2015(58 \%)$.

Table 1: Year wise insertion.

\begin{tabular}{|llll|}
\hline Year & $\begin{array}{l}\text { Total } \\
\text { deliveries }\end{array}$ & $\begin{array}{l}\text { PPIUCD } \\
\text { inserted }\end{array}$ & Percentage \\
\hline 2010 & 11335 & 226 & $1.99 \%$ \\
\hline 2011 & 14771 & 1176 & $7.96 \%$ \\
\hline 2012 & 13893 & 3606 & $25.95 \%$ \\
\hline 2013 & 13155 & 4860 & $36.94 \%$ \\
\hline 2014 & 12967 & 6777 & $52 \%$ \\
\hline 2015 & 15083 & 8790 & $58 \%$ \\
\hline
\end{tabular}

\section{Parity}

Maximum acceptance was seen among primipara $74.74 \%$. Among this maximum acceptance was seen in the year $2014(74.1 \%)$. Multipara showed an acceptance rate of $25.26 \%$. $42.4 \%$ insertion rate among multipara was seen in the year 2013 and 2015.

Table 2: Parity.

\begin{tabular}{|lllll|}
\hline Year & Primi & Percentage & Multi & Percentage \\
\hline 2010 & 135 & $59.7 \%$ & 91 & 40.3 \\
\hline 2011 & 715 & $60.8 \%$ & 461 & 39.2 \\
\hline 2012 & 2307 & $63.9 \%$ & 1299 & 36.1 \\
\hline 2013 & 2816 & $57.6 \%$ & 2046 & 42.4 \\
\hline 2014 & 5016 & $74.1 \%$ & 1761 & 25.9 \\
\hline 2015 & 5801 & $57.6 \%$ & 2989 & 42.4 \\
\hline
\end{tabular}

Mode of delivery

$50.5 \%$ had PPIUCD insertion following caesarean section.

Table 3: Mode of delivery.

\begin{tabular}{|ll|lll|}
\hline Year & $\begin{array}{l}\text { Vaginal } \\
\text { deliveries }\end{array}$ & $\%$ & LSCS & $\%$ \\
\hline 2010 & 214 & 1.8 & 12 & 0.1 \\
\hline 2011 & 817 & 5.53 & 359 & 2.4 \\
\hline 2012 & 1353 & 9.73 & 2253 & 16.2 \\
\hline 2013 & 1942 & 14.76 & 2918 & 22.18 \\
\hline 2014 & 3366 & 25.96 & 3411 & 26.31 \\
\hline 2015 & 4903 & 32.51 & 3887 & 25.78 \\
\hline
\end{tabular}


Among $49.5 \%$ of patients accepting after vaginal delivery $45.9 \%$ was within ten minutes of delivery and $3.5 \%$ was within 48 hours after delivery.

\section{Follow up}

Out of 25345 patients (total inserted), 8721 came for follow up. 1219 had complaints. It was observed that 758 had missed thread, 461 had expulsion. 7253 patients did not have any complaints
Table 4: Vaginal delivery.

\begin{tabular}{|lll|}
\hline Year & Post placental & Immediate postpartum \\
\hline 2010 & $199(93.12 \%)$ & $15(7.01 \%)$ \\
\hline 2011 & $739(90.56 \%)$ & $78(9.54 \%)$ \\
\hline 2012 & $1281(94.74 \%)$ & $72(5.32 \%)$ \\
\hline 2013 & $1815(93.46 \%)$ & $127(6.54 \%)$ \\
\hline 2014 & $3083(91.6 \%)$ & $283(8.4 \%)$ \\
\hline 2015 & $4548(92.75 \%)$ & $355(7.24 \%)$ \\
\hline
\end{tabular}

Table 5: Follow-up statistics.

\begin{tabular}{|c|c|c|c|c|c|c|}
\hline Year & Total & Expulsion & $\%$ & Missing Strings & $\%$ & No complaints \\
\hline 2010 & 3 & 1 & 33 & & & \\
\hline 2011 & 267 & 21 & 7.8 & & & \\
\hline 2012 & 1575 & 79 & 5 & 173 & 10.98 & 1323 \\
\hline 2013 & 1780 & 89 & 5 & 196 & 11 & 1495 \\
\hline 2014 & 2455 & 138 & 5.6 & 99 & 4.03 & 2216 \\
\hline 2015 & 2643 & 133 & 5.03 & 290 & 10.97 & 2219 \\
\hline
\end{tabular}

\section{DISCUSSION}

Ours is an apex institute where high risk cases are referred from all over Tamil Nadu and some parts of Andra Pradesh. Our institution has a well-equipped obstetric ICU with 11 beds to handle these challenging cases. We have pioneered in the introduction of PPIUCD in Tamil Nadu and have been the training centre for TOT (Trainer of Trainees).

When the programme first began, the insertion rate was very low since many senior obstetricians were apprehensive and objected PPIUCD insertion. Programme which was introduced earlier was abandoned due to high expulsion rate and fear of perforation. Even after insertion when patients went to the Peripheral health centers the doctors, staff nurses, ANMs (Auxillary Nurse Midwives) and VHNs (Village Health Nurses) counseled these patients against its use as they were not aware of the programme and held a firm belief that it would do more harm. Gradually awareness was created about the advantages of PPIUCD and emphasis given on the correct technique of insertion with the use of Kellys placental forceps by trained persons. It was stressed that with correct techniques the expulsion rates would be very low. This served to dispel the myths and misconceptions regarding perforation and expulsion. Even though the expulsion rate is high (4-5\%) compared to interval IUCD it should be borne in mind that the benefit of $95 \%$ retaining their PPIUCD is of utmost importance given the fact that most of the deliveries in Tamil Nadu are institutional.

In high risk patients with medical complications like heart disease, thromboembolism in pregnancy, chronic renal disorders, severe preeclampsia, eclampsia etc. where sterilization is deferred, PPIUCD remains a safe and effective method of contraception. Also in patients where sterilization is deferred for neonatal complications like birth asphyxia, prematurity, infant of diabetic mother, IUGR especially during caesarean section PPIUCD stands out as the best contraceptive choice.

In the present study a positive increasing trend is noted from 2010 to 2015. An important reason for the success of the programme in our institute is antenatal counseling given to patients and their family members which helped them clear doubts and made them more receptive to its use.

Present study has a higher acceptance rate among primipara. Similar observation was found in a study by Maluchuru S et al, Mishra S, Gautam R et al and Vidyarama $\mathrm{R}$ et al found a higher acceptance in primipara which were $15.42 \%, 13.76 \%, 71.91 \%$ and $15.47 \%$ respectively. ${ }^{3-6}$

In the present study, the acceptance among LSCS patients and vaginally delivered patients were $50.5 \%$ and $49.5 \%$ respectively. Borthakur $\mathrm{S}$ et al found more than $50 \%$ acceptors among patients undergoing caesarean section. ${ }^{7}$ Similarly results were shown in other studies, Gautam R et al (LSCS: 36.09\%, NVD: 11.33\%) and Jairaj S et al. Telangana (LSCS: 43.9\%, NVD: 6.3\%). ${ }^{5,8}$ Among patients delivering vaginally higher acceptance was seen with postplacental insertion $(45.9 \%)$ whereas in the group receiving insertion within first 48 hours was only $(3.5 \%)$ showing that acceptability is higher if insertion is done within 10 minutes of delivery of placenta.This is similar to study by Goswami et al, who showed that acceptance 
and complications are lesser with insertion done within first 15 minutes. ${ }^{9}$

In the present study, missing thread was the most common complication $(9.25 \% \%)$. It is similar to Maluchuru S et al (16\%), in a study in Central India by Kanhere AV et al. ${ }^{3,10}$ Expulsion was the most common complication $(22 \%)$.

The number of patients who returned for follow up was considerably less in 2010 and 2011 which was stepped from 2012 onwards which can be attributed to the fact that motivation on the part of the health care personnel has instilled confidence in the safety of PPIUCD among its users.

\section{CONCLUSION}

From the present study it is evident that PPIUCD serves as an effective contraceptive tool utilizing the opportunity of institutional deliveries especially in Tamil Nadu where 99\% of deliveries are institutional. This overcomes the lacunae of providing contraception to women who do not return for follow up to health facilities due to competing demands after delivery. Over the years the increase in training of health care providers and their continued motivation of patients has made PPIUCD a widely accepted method of contraception.

\section{Funding: No funding sources}

Conflict of interest: None declared

Ethical approval: The study was approved by the Institutional Ethics Committee

\section{REFERENCES}

1. Ministry of health and family welfare/Chapter 9/ Annual report. Available at http://mohfw.nic.in/WriteReadData/1892s/Chapter91 5.pdf

2. Cleland J, Bernstein S, Ezeh A, Faundes A, Glasier A, Innis J. Family planning: the unfinished agenda. Lancet. 2006;368:1810-27.
3. Maluchuru S, Aruna V, Prabhavathi N. Post-partum intrauterine device insertion: 2 years' experience at tertiary care center in Guntur medical college/govt general hospital, Guntur. J Dental Med Sci. 2015;14(3):56-61.

4. Mishra S. Evaluation of safety, efficacy, and expulsion of post-placental and intra-cesarean insertion of intrauterine contraceptive devices (PPIUCD). J Obstet Gynaecol India. 2014;64(5):33743.

5. Gautam R, Arya KN, Kharakwal S, Singh S, Trivedi M. Over view of immediate PPIUCD application in Bundelk hand region. J Evol Med Dent Sci. 2014;3(36):9518-26.

6. Vidyarama R, Nagamani T, Prasad K. PPIUCD as a long acting reversible contraceptive (larc): an experience at a tertiary care centre. Int $\mathbf{J}$ Sci Res. 2015;4(5):5-7.

7. Borthakur S, Sarma AK, Alakananda. Acceptance of post-partum intra-uterine contraceptive device (ppiucd) among women attending Gauhati Medical College and Hospital (GMCH) for delivery between January 2011 to December 2014 and their follow up. J Evol Med Dent Sci. 2015;4(92):15756-8.

8. Jairaj S, Dayyala S. A cross sectional study on acceptability and safety of IUCD among postpartum mothers at tertiary care hospital, Telangana. J Clin Diag Res. 2016;10(1):LC01-4.

9. Goswami G, Yadav K, Patel A. A prospective study to evaluate safety, efficacy and expulsion rate of post placental insertion of intra uterine device. J Evol Med Dent Sci. 2015;4(56):9770-74.

10. Kanhere AV, Pateriya P, Jain M. Acceptability and feasibility of immediate postpartum IUCD insertion in a tertiary care centre in Central India. Int J Reprod Contracept Obstet Gynecol. 2015;4:179-84.

Cite this article as: Mahadevan G, Chandika NB. Evaluation of safety, efficacy, acceptance and expulsion of post placental intrauterine contraceptive device in a tertiary care centre. Int J Reprod Contracept Obstet Gynecol 2018;7:542-5. 